\title{
Technology-Enhanced Learning and the Pursuit of Sustainability
}

\author{
Anna Visvizi ${ }^{1,2, *(1)}$ and Linda Daniela ${ }^{3}$ \\ 1 School of Business \& Economics, Deree College-The American College of Greece, 153-42 Athens, Greece \\ 2 Effat College of Business, Effat University, Jeddah P.O. Box 34689, Saudi Arabia \\ 3 Scientific Institute of Pedagogy, University of Latvia, Imantas 7th line, 1, LV 1083 Riga, Latvia \\ * Correspondence: avisvizi@acg.edu
}

Received: 23 July 2019; Accepted: 24 July 2019; Published: 25 July 2019

check for updates

\begin{abstract}
The inroads of sophisticated technologies and related applications in the field of education trigger several developments related not only to the processes of managing education institutions across levels and domains but also pertaining to approaches to teaching and learning. As advances in technology impact all aspects of life, when adopting and adapting to these advances, the education sector is expected to respond to issues and processes that current technological revolution triggers in the entire society. Hence, effective and forward-looking manner of managing technological advances in the education sector today is a necessity to ensure sustainability of that sector in the future. The objective of this Special Issue was to reflect on these issues, to identify the key questions that have to be addressed in this context, and to encourage new critical insights into these developments.
\end{abstract}

Keywords: technology-enhanced learning (TEL); advanced learning technologies (ALT); sustainable development goals (SDGs); sustainability; sustainable education

\section{Introduction}

The inroads of sophisticated technologies and related applications in the field of education caused several developments as regards the processes of managing education institutions across levels and domains as well as regards the ways and approaches to teaching and learning. As advances in technology impact all aspects of life, when adopting and adapting to these advances, the education sector is also expected to respond to issues and processes that current technological revolution triggers in the society. This means, for instance, that education institutions have to adapt to the changing learning styles that the new generation of learners is responsive to [1]. It also means that the curriculum has to be redesigned in view of equipping students with skills and competencies needed to cope with challenges and opportunities of today [2]. As downsides to rapid spread and adoption of technology can also be identified, especially as regards the foundational values and principles that define our societies [3,4], the education sector must reiterate its role as the bearer of those values and principles.

\section{The Paradox of Information Asymmetry in Education}

In this context, the fundamental question that needs to be addressed is if educational institutions are effectively preparing students to face current and future challenges. Are students equipped with skills and competencies that allow them to actively engage in their future professional and civic duties and responsibilities? Are the skills and competencies students acquire conducive to fostering the principles and objectives associated with Sustainable Development Goals (SDGs)? These questions become particularly relevant in the context of discussions on the use and value added of technology-enhanced learning (TEL). To put it differently, can advanced learning technologies (ALT) promote the acquisition of skills and competencies that will enable the promotion and attainment 
of SDGs? The thrust of the argument here is that today's educators are in essence preparing current generations of students to face a reality that is yet to unfold. We call it the information asymmetry paradox in education. In other words, if today's educators, and clearly the entire education sector, are to prepare current students to face future challenges and opportunities, they must anticipate nascent developments, tendencies, and trends. To this end, smart as well as ethically and socially sensitive use of technology might be the key to achieve that. However, are the professors prepared to do that?

Effective and forward-looking manner of managing advances in technology in the education sector today is a necessity to ensure sustainability of that sector in the future. Sustainability, in this case, is defined as the capacity of the education sector to adopt, adapt, and respond to changes taking place in society writ large [5]. Smart sustainable education is a concept and an approach to education where ideas of how to use technology effectively in the educational process are brought together with smart approaches designed to support learning. Smart education is also described as learning supported by a variety of tech-enabled smart devices, e.g., smartphones and tablets. From a different angle, studies exist where the term 'smart' is derived from specific attributes of students, i.e., SMART-Social; Motivated; Anywhere, Anytime; Resource enriched; Technology embedded [6] or Specific, Measurable, Achievable, Relevant, and Timed [7].

\section{Advances in Technology and the Plea of Universal Knowledge: Key Topics Addressed in the Discussion}

Challenges to the educational process never stop and ways of navigating them are always in demand. The hope is nevertheless that teaching and learning will continue, cognitive processes will develop, and the plea of universal knowledge available and accessible to everyone will be reached [8]. The inroads of technology in the processes of teaching and learning bear the promise attaining just that [9-11]. The problem, though, is that educators may not necessarily be skilled enough to use technology in the teaching process efficiently [12-14].

Considering the above, the objective of this Special Issue was to trigger a discussion on developments in the education sector, especially regarding its role in fostering the development of inclusive and sustainable society. Clearly, the 21st century exposes our societies to unprecedented social, economic, and political challenges, where environmental concerns, exclusion, and migration pressure add to the pace at which new challenges are born [15]. The education sector and all stakeholders, i.e., the educational institutions, the faculty, the students, the administration, the families, the decision-makers, the business sector, and the entire society, have the obligation to effectively respond to these nascent risks and emerging challenges.

This Special Issue sought to map current developments in the education sector to-against that backdrop-examine how advances in technology are being implemented at primary, secondary, and tertiary levels of education and what to make of it. The papers included in this Special Issue examine the broader context that influences the possibility of reaping the benefits of technology-enhanced learning (TEL) in the education sector today. The topics addressed include, somewhat paradoxically, professors' perceptions of the use and ease of use of technology in classroom; the necessity of a renew approach to performance measurement, management and appraisal in higher education institutions (HEI), as well as the underdiscussed issue of bullying in HEI. Regarding information and communication technology (ICT)-enhanced novel teaching and learning methods, i.e., ALT, the papers included in this Special Issue explore the value-added of relying on knowledge graphs in the teaching process, the use of coding, or animated presentations. A significant thread in the discussion is formed by the question of the usefulness of virtual reality in the classroom. The rest of the discussion is defined by questions of robotics in education, diverse forms, and combinations of online and offline learning, gamification, and flipped classes. The following paragraphs offer a more detailed overview of the topics and issues addressed in this Special Issue. 


\section{Overview of the Content of the Special Issue}

Linda Daniela, Anna Visvizi, Calixto Gutiérrez-Braojos, and Miltiadis D. Lytras explore the very question of the use and value-added of technology in the classroom. Their paper titled 'Sustainable Higher Education and Technology-Enhanced Learning (TEL)' draws from the outcomes of an international survey conducted among professors at tertiary education institutions. As the authors argue, the field of education is not immune to advances in sophisticated information and communication technology (ICT). The question is, though, to what extent and how technology-enhanced teaching and learning (TEL) can enhance teaching and learning? How in these circumstances TEL can play the role of the key lever of sustainable socioeconomic growth and development? The initial point of departure for this study was consistent with the well-referenced in the literature thesis that TEL has profound value added in view of enhancing the teaching and learning process. Yet, as the outcomes of the survey underpinning the discussion in this paper suggest, there is much more at stake than that. Indeed, the authors argue, several conditions need to be fulfilled if technology is to serve as a benefit, and not an obstacle to teaching and learning, and thus boost the delivery of quality education. This paper outlines them.

Emmanouil Varouchas, Miguel-Ángel Sicilia, and Salvador Sánchez-Alonso offer a new take on performance measurement in HEI. In their paper titled 'Academics' Perceptions of Quality in Higher Education Shaping Key Performance Indicators', the authors make a case for integrating 'quality' in educational programs. Accordingly, drawing from the outcomes of qualitative interviews conducted with HEI administrators and professors, several independent dimensions of 'quality' are discerned, quantified, and turned into performance indicators (KPIs). As the authors argue, these KPIs will provide valuable insights into improving teaching, learning, and assessment and will eventually lead to sustainable curricula. Research findings outline the significance of the time invested to design and update a course, indicate that technology-enhanced learning solutions are perceived as key quality drivers, and point out the need to align courses with industry requirements and real-world problems. Additionally, findings indicate that the quality and impact of teaching and learning is promoted by the multi/interdisciplinary character of a course, the engagement of students in interactive discussions, and student research as part of summative assessment. The main contribution of this research is an analytic discussion of perceptions of higher education administrators and professors about quality, leading to a significant enrichment of the relevant literature.

Ambreen Anjum, Amina Muazzam, Farkhanda Manzoor, Anna Visvizi, and Raheel Nawaz reopen the question of bullying in higher education institutions (HEI). In their paper titled 'Mediating Bullying and Strain in Higher Education Institutions: The Case of Pakistan', the authors argue that the specific way bullying unfolds in HEI remains largely underdiscussed. Based on the outcomes of a survey conducted across HEI in Pakistan, by reference to structural equation modeling, using Amos-20, this paper offers new insights into our understanding of the scope and features of bullying in HEI. This paper does more than that. It also suggests strategies employers and victims could employ to cope with the adverse implications of bullying. The key findings of this research are: (i) a positive correlation exists between the degree of workplace bullying and strain levels; (ii) more frequently than not, female employees, younger employees, and employees in junior positions are victims of bullying; (iii) bullying and strain can be fully mediated only when both emotion-focused and problem-focused coping strategies are employed in synergy.

Yang Chi, Yue Qin, Rui Song, and Hao Xu explore the use of knowledge graphs as a tool in the teaching and learning process. Their paper titled 'Knowledge Graph in Smart Education: A Case Study of Entrepreneurship Scientific Publication Management' presents the design of a scientific publication management model to integrate scientific metadata based on the knowledge graph and data analysis technologies. Based on this model, an interdisciplinary transregional multiple application platform could be realized for scientific resource retrieval and analysis, the purpose of which is to enhance scientific retrieval efficiency and reduce learning difficulty in the scientific domains and encourage nonresearchers to utilize scientific resources in their study and work. Finally, to evaluate this model, the use of the case of an entrepreneurship scientific publication management prototype 
system was implemented. This work not only favors student's learning for sustainability through analysis and knowledge management functions, but also promotes their awareness, comprehensive thinking, and the skills to deal with the issues of sustainability in their future work.

Celalettin Özden and Murat Tezer in their paper titled 'The Effect of Coding Teaching on Students' Self-Efficacy Perceptions of Technology and Design Courses' examine the effect of coding teaching on students' self-efficacy perceptions of technology and design courses. A consecutive-explanatory design in a combined research model was used in this study. The qualitative dimension of the research was carried out through a random experimental design with pre/post-tests with controlled groups, and the qualitative dimension was conducted through interview techniques. The participants were seventh-grade students from Şehit Hüseyin Ruso Secondary school in Lefkoşa, North Cyprus, in the 2016-2017 academic year. The quantitative data were collected through the "Technology and Design Course Self-efficacy Perception Scale", developed by the researcher, and the qualitative data were collected through interview forms oriented around "Coding Teaching and Revised Technology and Design Course Teaching Program". The quantitative data were analyzed through related and unrelated sampling t-test, Cohen's d effect size coefficiency, and two-way variance analyses, and the qualitative data were analyzed through content analysis. A significant difference was observed between the students, taking coding teaching, and self-efficacy perceptions of Technology and Design courses compared to the control groups. Besides, it was noted that students taking coding teaching courses exhibited a positive attitude towards the course, and they practiced their metacognitive thinking and social skills at top levels. Based on the students' views, it is obvious that coding teaching has a positive effect on their self-efficacy perceptions of the subject.

Yenchun Jim Wu, Chih-Hung Yuan, and Chia-I Pan in their paper titled 'Entrepreneurship Education: An Experimental Study with Information and Communication Technology' explore how TEL can boost skills associated with entrepreneurship. As the authors argue, entrepreneurship is regarded as a new science in the promotion of economic development, which has led to rapid development in entrepreneurship education. The growing number of students enrolled in entrepreneurship programs creates unprecedented challenges on educators. Although multiple teaching and learning activities are adopted in entrepreneurship education, these are mainly carried out using traditional classroom lectures, case studies, and group discussions. ICT is used to enhance the effectiveness of traditional teaching methods and competency training. PowToon is a web-based ICT tool that allows teachers and students to quickly and easily create animated presentations. Using quasi-experimental design and qualitative method, this study is to examine whether PowToon is an effective tool for business plan presentation. The outcomes of the study suggest that the animated presentations attracted more investment than the groups that did not prepare animated videos. This suggests that animated, rather than static, presentations serve as a more efficient tool to present business ideas to investors.

Vicente Román-Ibáñez, Francisco A. Pujol-López, Higinio Mora-Mora, Maria Luisa Pertegal-Felices, and Antonio Jimeno-Morenilla examine the use of virtual reality $(\mathrm{VR})$ in the teaching process. In their paper titled 'A Low-Cost Immersive Virtual Reality System for Teaching Robotic Manipulators Programming', the authors argue that laboratory tasks are a powerful pedagogical strategy for developing competencies in science and engineering degrees. They allow students understand in a practical way the theoretical topics explained in the classroom. However, performing experiments in real conditions is usually expensive in terms of time, money, and energy, as it requires expensive infrastructures that are generally difficult to maintain in good conditions. To overcome this problem, virtual reality has proven to be a powerful tool to achieve sustainability, making it easy to update laboratories without the need to acquire new equipment. Moreover, the ability to introduce practical knowledge into classrooms without leaving them makes virtual laboratories capable of simulating typical operating environments as well as extreme situations in the operation of different devices. A typical subject in which students can benefit from the use of virtual laboratories is robotics. In this work, we will develop an immersive virtual reality (VR) pedagogical simulator of industrial robotic arms for engineering students. With the proposed system, students will know the effects of their own designed trajectories on several different robotic arms and 
cell environments without having to buy all of them and being safe of damaging the cell components. The simulation will be checking for collisions of the elements in the scene and alert the student when they happen. This can be achieved with a robotic simulator, but the integration with immersive VR is intended to help students better understand robotics. Moreover, even having a real robotic arm available for students, with this proposed VR method, all the students have the opportunity to manage and learn his own version of the robotic cell, without waiting times generated by having less robotic arms than students in the classroom.

In the following paper on VR and its value-added in the teaching process, Rafael Molina-Carmona, María Luisa Pertegal-Felices, Antonio Jimeno-Morenilla, and Higinio Mora-Mora examine to what extent VR can enhance students' spatial ability. In their paper titled 'Virtual Reality Learning Activities for Multimedia Students to Enhance Spatial Ability', the authors argue that it is possible to design VR learning activities that can help students to develop their spatial ability. To prove the hypothesis, the authors conducted an experiment consisting of training the students using an on-purpose learning activity based on a virtual reality application and assessing the possible improvement of the students' spatial ability through a widely accepted spatial visualization test. The learning activity consisted of a virtual environment where some simple polyhedral shapes are shown and manipulated by moving, rotating, and scaling them. The students participating in the experiment were divided into a control and an experimental group, carrying out the same learning activity with the only difference of the device used for the interaction: a traditional computer with screen, keyboard, and mouse for the control group, and virtual reality goggles with a smartphone for the experimental group. To assess the experience, all the students have completed a spatial visualization test twice: just before performing the activities and four weeks later, once all the activities were performed. The results of the test showed that there was an improvement in the test results for both groups, but the improvement was significantly higher in the case of the experimental group.

Sung Eun Jung and Eun-sok Won in their paper titled 'Systematic Review of Research Trends in Robotics Education for Young Children' investigate: (1) the definition of robotics education; (2) thematic patterns of key findings; and (3) theoretical and methodological traits. The results of the review present a limitation of previous research in that it has focused on robotics education only as an instrumental means to support other subjects or STEM education. This study identifies that the findings of the existing research are weighted toward outcome-focused research. Lastly, this study addresses the fact that most of the existing studies used constructivist and constructionist frameworks not only to design and implement robotics curricula but also to analyze young children's engagement in robotics education. Relying on the findings of the review, this study suggests clarifying and specifying robotics-intensified knowledge, skills, and attitudes in defining robotics education in connection to computer science education. In addition, this study concludes that research agendas need to be diversified and the diversity of research participants needs to be broadened. To do this, this study suggests employing social and cultural theoretical frameworks and critical analytical lenses by considering children's historical, cultural, social, and institutional contexts in understanding young children's engagement in robotics education.

Muqiang Zheng, Chien-Chi Chu, Yenchun Jim Wu, and Wanxing Gou in their paper titled 'The Mapping of On-Line Learning to Flipped Classroom: Small Private Online Course' examine the integration of the On-line to Off-line $(\mathrm{O} 2 \mathrm{O})$ classroom development and their value-added in microeconomics courses. The results of the study revealed significant improvements in students learning outcomes after $\mathrm{O} 2 \mathrm{O}$ mode was implemented. In comparison with traditional teaching methods, $\mathrm{O} 2 \mathrm{O}$ teaching significantly improve students' learning results not only as regards professional knowledge but also as regards their capabilities.

Donglei Song, Daqian Shi, Rusi Wang, and Hao Xu, in their paper titled 'Splitting and Combining as a Gamification Method in Engaging Structured Knowledge Learning', explore the gamification method and the knowledge structure of computer science. The authors assess the gamification method of "splitting and combining" (SC) to encourage students to finish the process of learning structured 
knowledge at the university. The results show that this method works well in promoting learning enjoyment. Moreover, splitting demonstrates better performance than combining. Accordingly, SC should be considered as the method when recommending a gamification method to engage students in structural learning assistance in future smart university education.

Summing up, as the papers briefed above suggest, the use of technology in the classroom bears considerable promise. It remains nevertheless a challenge how to create an enabling environment to encourage professors to embark on TEL, how to motivate students to remain committed, and finally, how to use the variety of methods and tools effectively and responsibly. By addressing some of these questions, this Special Issue sought to ignite a more thorough debate on those topics.

Author Contributions: The authors contributed equally to this paper.

Funding: This research received no external funding.

Acknowledgments: Anna Visvizi would like to thank Effat University in Jeddah, Saudi Arabia, for funding the research reported in this paper through the Research and Consultancy Institute.

Conflicts of Interest: The authors declare no conflict of interest.

\section{References}

1. Daniela, L.; Visvizi, A.; Lytras, M.D. How to Predict the Unpredictable: Technology-Enhanced Learning and Learning Innovations in Higher Education. In The Future of Innovation and Technology in Education: Policies and Practices for Teaching and Learning Excellence; Visvizi, A., Lytras, M.D., Daniela, L., Eds.; Emerald Publishing: Bingley, UK, 2018; pp. 11-26. ISBN 9781787565562. [CrossRef]

2. Visvizi, A.; Lytras, M.D.; Daniela, L. Education, Innovation and the Prospect of Sustainable Growth and Development. In The Future of Innovation and Technology in Education: Policies and Practices for Teaching and Learning Excellence, Emerald Studies in Higher Education, Innovation and Technology; Visvizi, A., Lytras, M.D., Daniela, L., Eds.; Emerald Publishing: Bingley, UK, 2018; pp. 297-305. ISBN 9781787565562. [CrossRef]

3. Mora-Cantallops, M.; Sánchez-Alonso, S.; Visvizi, A. The influence of external political events on social networks: The case of the Brexit Twitter Network. J. Ambient Intell. Humaniz. Comput. 2019. [CrossRef]

4. Visvizi, A.; Lytras, M.D. (Eds.) Politics and Technology in the Post-Truth Era; Emerald Publishing: Bingley, UK, 2019; ISBN 9781787569843.

5. Daniela, L.; Visvizi, A.; Gutiérrez-Braojos, C.; Lytras, M.D. Sustainable Higher Education and Technology-Enhanced Learning (TEL). Sustainability 2018, 10, 3883. [CrossRef]

6. Chun, S.; Kim, J.; Kye, B.; Jung, S.; Jung, K. Smart Education Revolution; 21st Books: Seoul, Korea, 2013.

7. Tofade, T.; Khandoobhai, A.; Leadon, K. Use of Smart Learning objectives to introduce continuing professional development into the pharmacy curriculum. Am. J. Pharm. Educ. 2012, 76, 1-7. [CrossRef]

8. Sicilia, M.A.; Visvizi, A. Blockchain and OECD Data Repositories: Opportunities and Policymaking Implications. Library Hi Tech 2018, 37, 30-42. [CrossRef]

9. Chan, T.W.; Roschelle, J.; Hsi, S.; Sharples, M.; Brown, T.; Patton, C.; Cherniavsky, J.; Pea, R.; Norris, C.; Soloway, E.; et al. One-to-one technology-enhanced learning: An opportunity for global research collaboration. Res. Pract. Technol. Enhanc. Learn. 2006, 1, 3-29. [CrossRef]

10. Berners-Lee, T.; Cailliau, R. WorldWideWeb: Proposal for a HyperText Project. 1990. Available online: https://www.w3.org/Proposal.html (accessed on 20 July 2019).

11. Mishra, P.; Koehler, M. Technological pedagogical content knowledge: Aframework for teacher knowledge. Teach. Coll. Rec. 2006, 108, 1017-1054. [CrossRef]

12. Tsinonis, T. How to Use ICT in the Classroom Effectively: The Technological Blend. In The Future of Innovation and Technology in Education: Policies and Practices for Teaching and Learning Excellence; Visvizi, A., Lytras, M.D., Daniela, L., Eds.; Emerald Publishing: Bingley, UK, 2018; pp. 111-126. ISBN 9781787565562. [CrossRef]

13. Pareto, L.; Willermark, S. TPACK In Situ: A Design-Based Approach Supporting Professional Development in Practice. J. Educ. Comput. Res. 2018. [CrossRef] 
14. OECD. ICT for Teaching. In TALIS 2018 Results (Volume I): Teachers and School Leaders as Lifelong Learners; TALIS, OECD Publishing: Paris, France, 2019. Available online: https://www.oecd-ilibrary.org/education/ictfor-teaching_3ddd8e5a-en (accessed on 22 July 2019).

15. Lytras, M.D.; Daniela, L.; Visvizi, A. (Eds.) Knowledge-Intensive Economies and Opportunities for Social, Organizational, and Technological Growth; IGI Global: Hershey, PA, USA, 2019; ISBN 9781522573470.

(C) 2019 by the authors. Licensee MDPI, Basel, Switzerland. This article is an open access article distributed under the terms and conditions of the Creative Commons Attribution (CC BY) license (http://creativecommons.org/licenses/by/4.0/). 